\title{
Studies on the Effect of the Capping Materials on the Spherical Gold Nanoparticles Catalytic Activity
}

\author{
Roshdi Seoudi ${ }^{1,2}$, Doaa A. Said ${ }^{3}$ \\ ${ }^{1}$ Spectroscopy Department, Physics Division, National Research Center, Cairo, Egypt \\ ${ }^{2}$ Department of Physics, College of Applied Science, Umm Al-Qura University, Makkah, Saudi Arabia \\ ${ }^{3}$ Physics Department, Faculty of Women, Ain Shams University, Cairo, Egypt \\ E-mail:rsmawed@yahoo.com \\ Received March 30, 2011; revised April 11, 2011; accepted April 18, 2011
}

\begin{abstract}
Size-controlled gold nanoparticles (AuNPs) were prepared in the presence of different capping materials (sodium citrate, cetyltrimethylammonium bromide (CTAB), and chitosan). The results obtained suggest that the AuNPs were synthesized with different particle size, which is controlled by changing the molar ratio between sodium citrate, (CTAB), and chitosan to $\mathrm{Au}$ (III). The catalytic activities of the AuNPs with different capping materials were studied for 4-nitrophenol reduction by $\mathrm{NaBH}_{4}$ as a model reaction. AuNPs with different capping materials is comparable from the value of the apparent rate constant of 4-nitrophenol reduction $\left(0.6 \times 10^{-3}, 1.9 \times 10^{-3}\right.$, and $\left.2.4 \times 10^{-3} \mathrm{~s}^{-1}\right)$ for sodium citrate, CTAB and chitosan. From the results, it is concluded that, AuNPs catalyzed the electron transfer process between $\mathrm{BH}_{4}^{-}$and nitro compounds with all the capping materials used AuNPs capped by chitosan were more active for the reduction than the other two.
\end{abstract}

Keywords: Gold Nanoparticle, Catalytic Activity, TEM, UV-VIS Spectroscopy

\section{Introduction}

Nanomaterials and its composites have become increasingly popular due to their size-specific, unique properties, and promising a breakthrough in the development of novel methods in medicine [1,2], and sensor [3,4]. Gold nanoparticle AuNPs, have received more attention due to their strong optical absorption in the visible region $[5,6]$, catalysis properties [7-9], and enhanced sensitivity in surface-enhanced Raman scattering (SERS) studies [10]. All the above properties are strongly affected by the size and shape of the AuNPs. Several methods are known and have been exploited for centuries and there are still many deficiencies in the development of stable colloids containing AuNPs of various sizes and shapes for precise application. All synthesis procedures must overcome thermodynamic principles, which predict that AuNPs will tend to agglomerate, collapsing the colloid via precipitation or flocculation of the particles. This tendency can be hindered by chemical species, which surround the particles, making particle agglomeration difficult. The synthesis of AuNPs in aqueous solution is still the general route. The most popular method for preparing AuNPs in water used the citrate to reduction of $\mathrm{HAuCl}_{4}$ under boiling conditions [11]. Colloidal $\mathrm{Au}$ nanospheres were prepared in CTAB [12]. Therefore, diverse approaches have been developed to the reduction of $\mathrm{Au}(\mathrm{III})$ salts in water [13-17] using different ligands as colloidal particle stabilizers [18-23]. Until around 1980, gold was not fully recognized for its catalytic ability. Recent techniques have shown AuNPs to be highly active, and it has the distinction of being the most highly active catalyst for the hydrochlorination of acetylene to produce vinyl chloride [24]. The complexities of catalyst fouling have given rise to a number of simulations that attempt to explain and predict catalytic fouling [25-28]. Gold has many unexpected properties that prevented earlier discovery of its catalytic potential. Unlike most other elements, gold does not have a stable oxide. It also does not follow the rule of thumb that other catalysts. The atomic radius of gold is smaller and its most stable state is gold III [29,30]. However, application prospects of conventional chemically synthesized nanomaterials are often complicated because of their toxicity, caused by contamination with chemical precursors or additives during their synthesis procedures [31]. Recently, much attention has been paid to chitosan due to its excellent properties such as biocompatibility, biodegradability, nontoxicity [32-36]. Chi- 
tosan is a natural polymer with abundant primary amino groups in its molecular structure; the structure is shown in Figure 1.

Chitosan was chosen as a protecting agent in synthesis of metal nanoparticles. Esumi et al. [37] reported the formation of gold-chitosan nanocomposites by adsorption of chitosan molecules on particle surfaces. Ballauff et al. [38] have shown that it is possible for chitosan to not only stabilize, but also reduce gold chloride into gold nanoparticles. AuNPs are highly active and it can be used to decrease the temperature catalysts in the number of important reactions such as $\mathrm{CO}$ oxidation and propylene epoxidation [39]. In this work, gold nanoparticle was prepared with different capping materials (sodium citrate, CTAB and chitosan) and used for catalysis of the reduction of 4-nitrophenol (4-NP) to study the effect of capping on the catalytic reduction which has not been demonstrated earlier.

\section{Experimental}

Cetlytrimethylammonium, sodium borohydried $\left(\mathrm{NaBH}_{4}\right)$, tri-sodium citrate, and hydrogen tetrachloroaurate (III) were purchased from Sigma-Aldrich. Medium-molecular-weight chitosan (2-amino-2-deoxy-(1-4)- $\beta$-D-glucopyranose) with a degree of deacetylation of $100 \%$ and, 4-Nitrophenol (reagent grade) was purchased from Fluka. All aqueous solutions were made with ultra-high-purity water purified.

\subsection{Samples Preparation}

\subsubsection{Preparation of AuNPs Capped by Sodium Citrate}

A $20 \mathrm{~mL}$ aqueous solution containing $2.5 \times 10^{-4} \mathrm{M}$ $\mathrm{HAuCl}_{4}$ and $2.5 \times 10^{-4}$ tri-sodium citrate was mixed in a conical flask. Next, $0.6 \mathrm{~mL}$ of ice cold $0.1 \mathrm{M} \mathrm{NaBH} 4$ solution was added to the solution all at once while stirring. The solution turned pink immediately after adding $\mathrm{NaBH} 4$, indication particle formation. The nanoparticle solutions were used in a catalytic reduction within $12 \mathrm{~h}$ after preparation. Citrate serves only as the capping agent since it cannot reduce gold salt at room temperature $\left(25^{\circ} \mathrm{C}\right)$.

\subsubsection{Preparation of AuNPs Capped by CTAB}

AuNPs capped by CTAB was prepared by mixing CTAB solution $(5.0 \mathrm{~mL}, 0.20 \mathrm{M})$ with $5.0 \mathrm{~mL}$ of $0.00050 \mathrm{M}$ $\mathrm{HAuCl}_{4}$. To the stirred solution, $0.60 \mathrm{~mL}$ of ice-cold $0.010 \mathrm{M} \mathrm{NaBH}_{4}$ was added, which resulted in the formation of a brownish yellow solution. Vigorous stirring of the solution was continued for $2 \mathrm{~min}$, then the solution was stirred, it was kept at $25^{\circ} \mathrm{C}$ without further stirring.

\subsubsection{Preparation of AuNPs capped by Chitosan}

A completely dissolved of chitosan solution, $0.04 \mathrm{gm}$ (20 $\mathrm{mg} / \mathrm{ml}$ ) in $1 \%$ acetic acid solution was prepared first; due to the poor solubility of chitosan, the mixture was vortexed to completely dissolve it and kept overnight. The solution was filtered through $30 \mu \mathrm{m}$ Millipore syringe filters to remove any impurities before use. $20 \mathrm{ml}$ of aqueous solution of $\mathrm{HAuCl}_{4}(10 \mathrm{mM})$ was added to a 40 $\mathrm{ml}$ chitosan solution under magnetic stirring for two hours and $8 \mathrm{ml}$ of $\mathrm{NaBH}_{4}(0.1 \mathrm{M})$ freshly prepared was added drop by drop. The solution turned brown immediately after addition of $\mathrm{NaBH}_{4}$; stirring continued until a transparent wine-red solution was obtained. The sample was kept at room temperature. The same procedure was repeated by adding $10 \mathrm{mM}$ of $\mathrm{HAuCl}_{4}$ to $40 \mathrm{ml}$ of chitosan nanoparticle.

\subsection{Catalytic Reduction of 4-Nitrophenol}

The photocatalysis reactions were carried out in standard quartz cuvette with a $1-\mathrm{cm}$ path length containing the reaction mixture, $1.4 \mathrm{~cm}^{3}$ of water, and $300 \mu \mathrm{L}$ of $2 \mathrm{mmol}$ $\mathrm{dm}^{-3}$ 4-nitrophenol were taken. Addition and proper mixing of $1 \mathrm{~cm}^{3}$ of aqueous $0.03 \mathrm{~mol} \mathrm{dm}{ }^{-3}$ sodium borohyride and $30 \mu \mathrm{L}$ of gold nanoparticle solution to the reaction mixtures caused the decrease in the intensity of the peak of 4-nitrophenol. The progress of the reduction of 4-NP was monitored in situ using a UV-visible spectrophotometer (Oceanoptics HR4000 Cg). The reaction temperature was held constant at room temperature

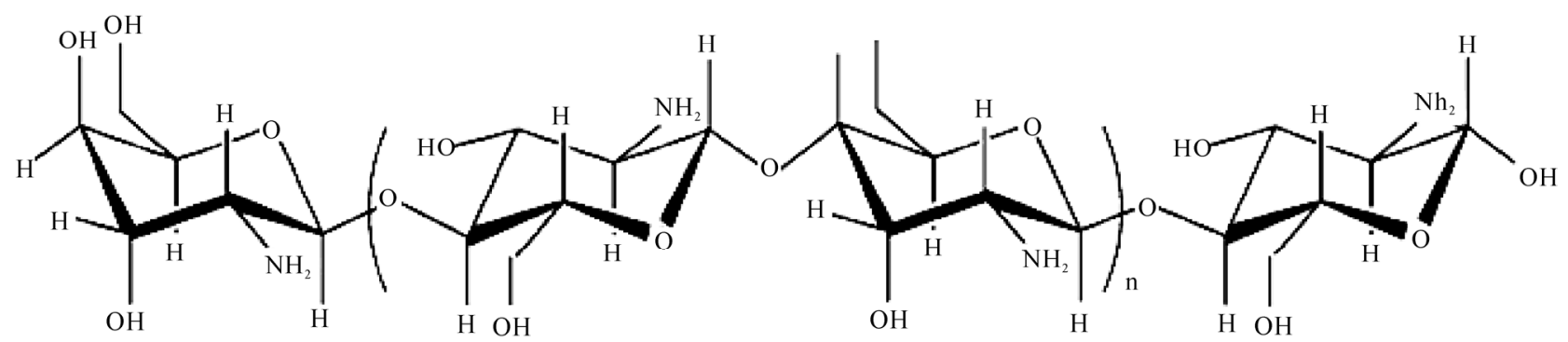

Figure 1. Chemical structure of chitosan. 
$\left(15^{\circ} \mathrm{C}\right)$ to reduce thermal effects on the catalytic rate. The time for the reduction started and completion of the reaction varies and depends upon the capped of the AuNPs.

\section{Results and Discussion}

\subsection{UV-Visible Spectra}

UV-vis absorption spectra of AuNPs capped by sodium citrate, CTAB, and chitosan are shown in Figures 2-4. The absorption spectrum of gold nanoparticle capped by sodium citrate shows a sharp peak at $514 \pm 3 \mathrm{~nm}$. The slow shift of the band position depends on the ratio of the gold salt and capping materials during the reaction processes. This peak is due to collective oscillation of the electrons in the conduction band due to the oscillation frequency, known as the surface plasmon oscillation. At resonance the amplitude of the local electric field in the particle, $E_{l}$ is enhanced as compared to the one of the applied field, $E_{o}$. In other words, complex local field factor $f_{l}=E_{l} / E_{o}$ greater the SPR. The position of the plasmon band for AuNPs capped by CTAB nearly the same as sodium citrate. In the other side this band was shifted to higher wavelength in the case of capped by chitosan and the change of the plasmon band more clearly than sodium citrate and CTAB. Chitosan is used as a stabilizing polymer for AuNPs because the dispersed solutions are due to formation of coordination bonds between $\mathrm{Au}$ ions and the amine and hydroxyl groups of chitosan and this chelation evenly disperses $\mathrm{Au}$ ions which reduced to form dispersed AuNPs of relatively uniform size. It is easy to change the particle size by changing the ratio between $\mathrm{Au}$ salt and chitosan and this change in the particle size is more clearly than sodium citrate and CTAB. This is may be due to the chemical reaction between the amine and hydroxyl group in chitosan and Au (III) more active than that of sodium citrate and CTAB.

\subsection{Transmission Electron Microscope Data}

Figure 5(a-f) shows a typical TEM images of gold nanoparticle capped by sodium citrate, CTAB and chitosan as well as the frequency $\%$ as a function of the average particle size (in the images). The samples that measured by TEM was chosen according to the plasmon band position. The ratio between the Au salt and capping for these samples was $(10: 20),(10: 5)$, and (10:20) for sodium citrate, CTAB, and chitosan, respectively. The images indicated that, the gold was prepared with particle size about $15 \mathrm{~nm}$ for all capping and some aggregation was appeared in AuNPs capped by chitosan.

\subsection{Catalytic Reduction of 4-Nitrophenol}

To obtained the AuNPs with different capping materials is an excellent catalyst for hydrogenation reaction, we

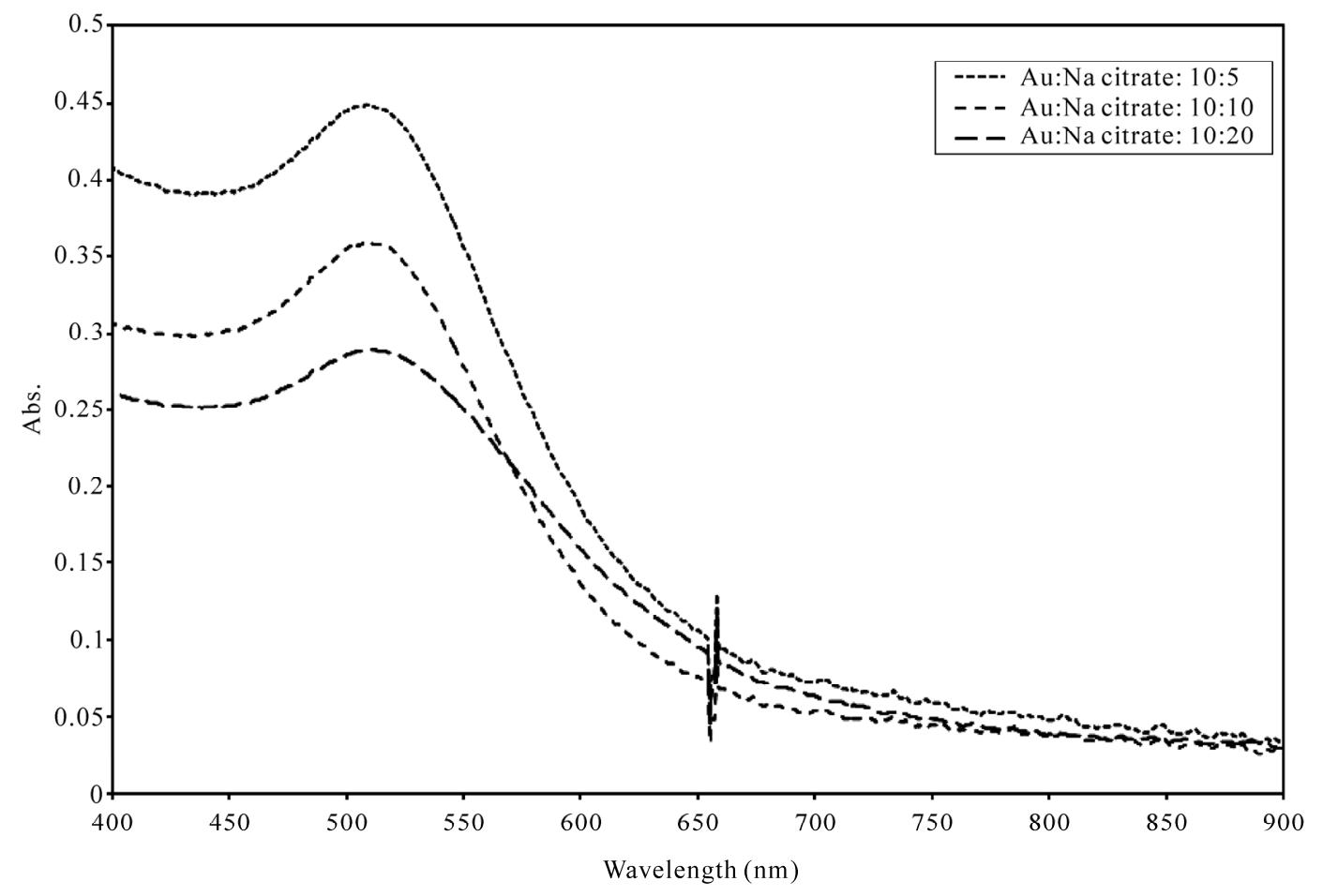

Figure 2. UV-vis spectrum of AuNPs prepared with different ratio from gold salt and capping material (sodium citrate). 


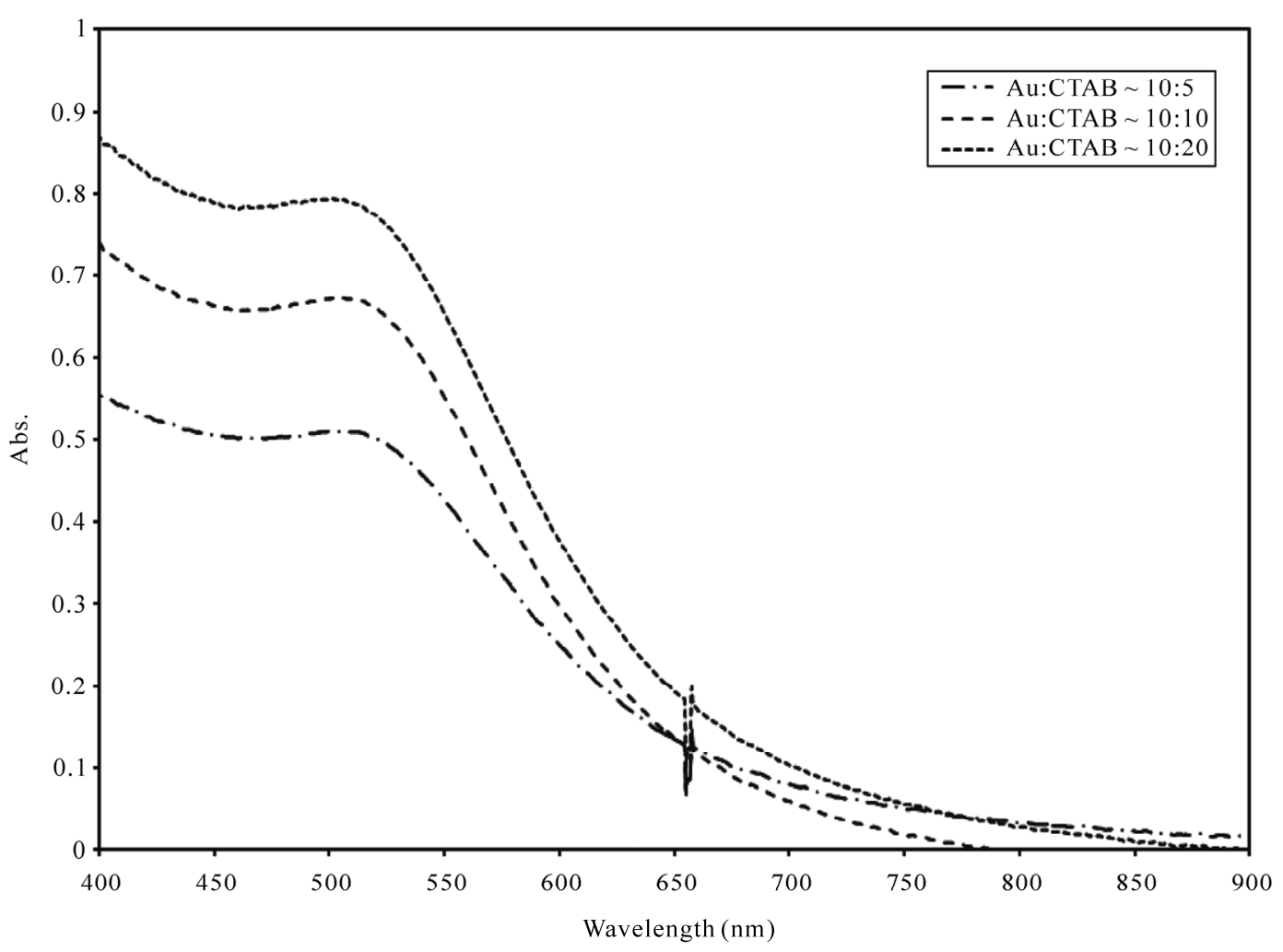

Figure 3. UV-vis spectrum of AuNPs prepared with different ratio from gold salt and capping material (Cetlytrimethylammonium bromide).

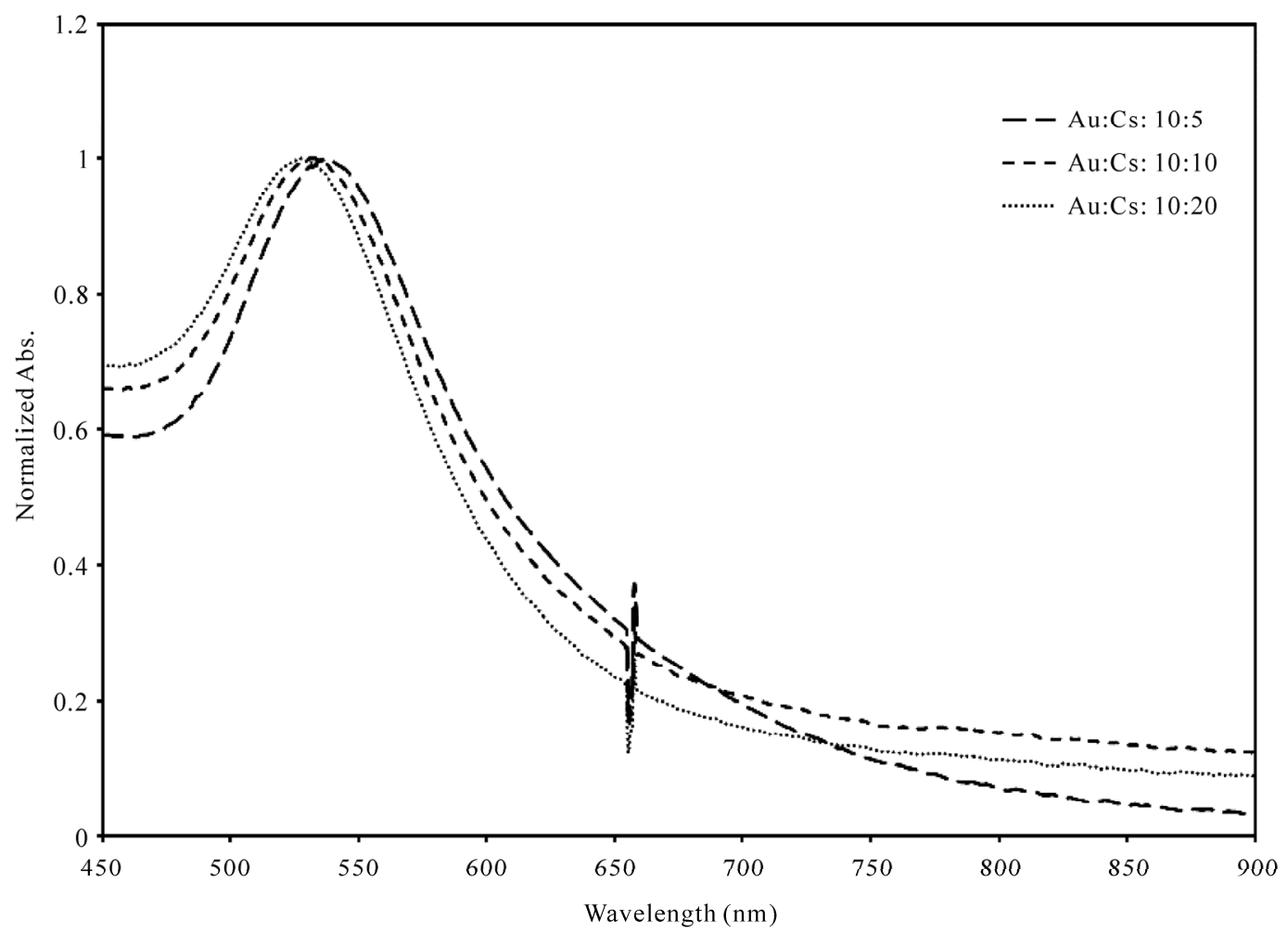

Figure 4. UV-vis spectrum of AuNPs prepared with different ratio from gold salt and capping material (chitosan). 


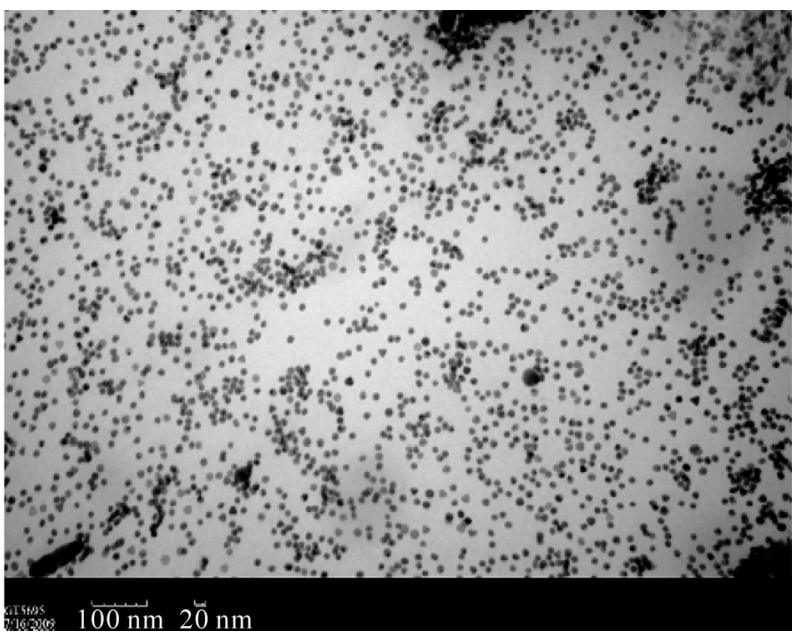

(a)

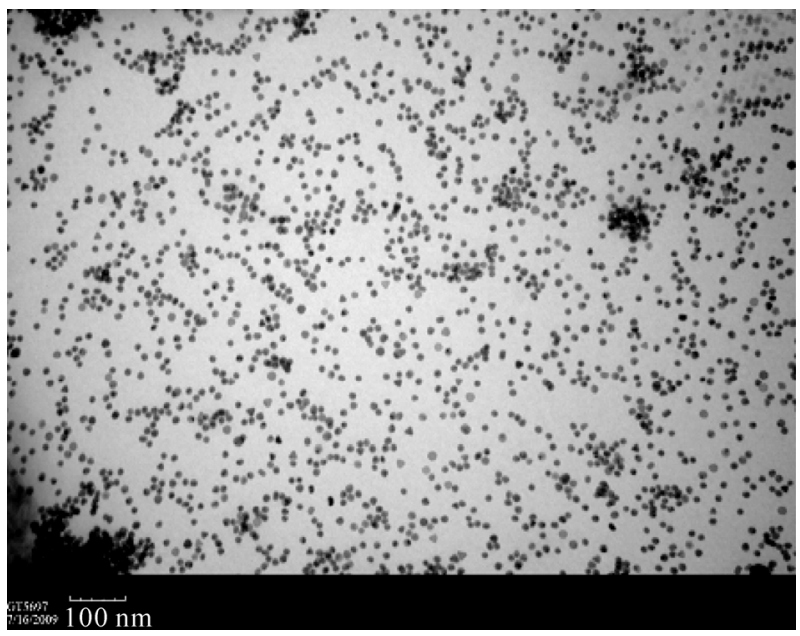

(c)

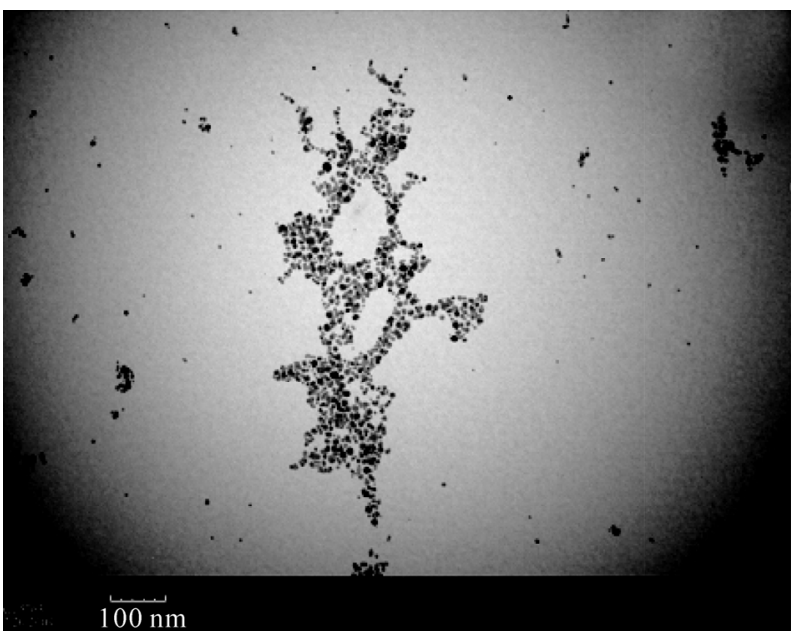

(e)

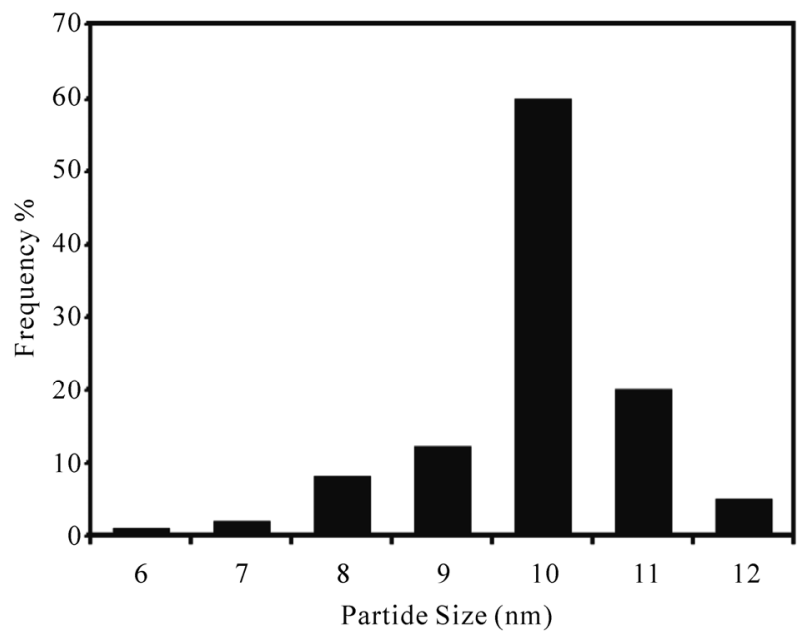

(b)

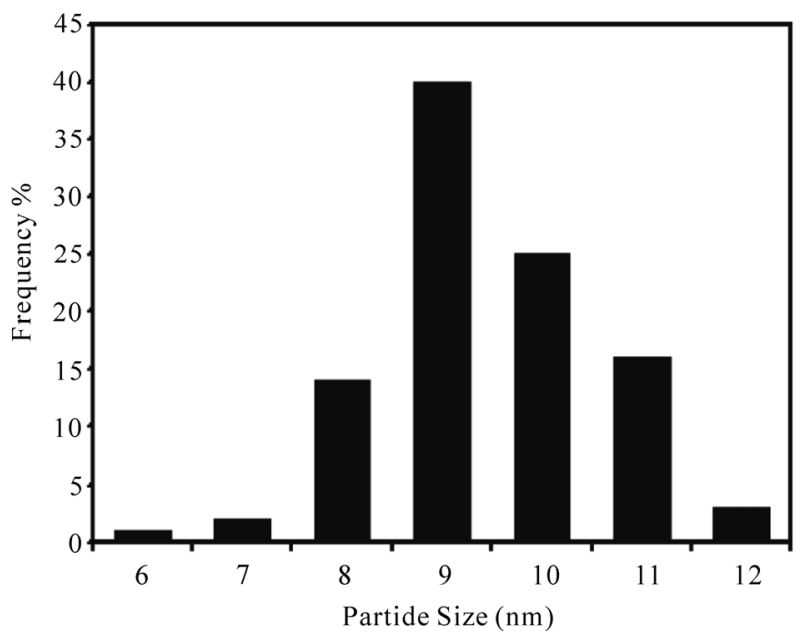

(d)

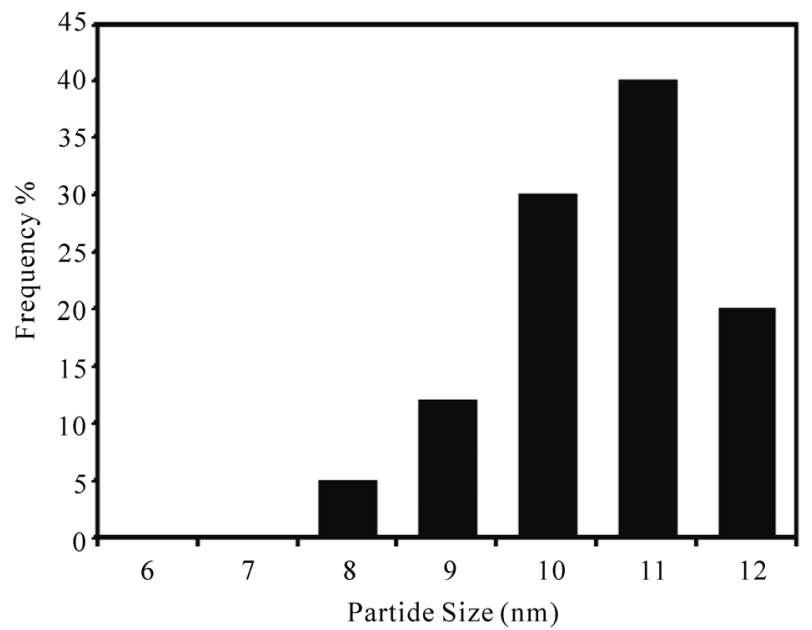

(f)

Figure 5. TEM images of AuNPs capped by sodium citrate (a) and its frequency \% as a function of the average particle size (b), CTAB (c) and its frequency \% as a function of the average particle size (d), and chitosan (e) and its frequency \% as a function of the average particle size (f). 
investigated the reduction of 4-nitrophenol by sodium borohydride without and with AuNPs. The reaction was chosen because UV-visible absorbance respond directly corresponds to the state of the reaction; therefore, rate constant can be derived from the intensity peaks. Figure 6 shows the ultraviolet-visible spectrum of the 4-NP without and with $\mathrm{NaBH}_{4}$. From this figure it is clear that; the two absorption beaks at 226 and $317 \mathrm{~nm}$ in the spectrum of (4-NP) assigned to $\pi \rightarrow \pi^{*}$ (from the ring of phenol) and $n \rightarrow \pi^{*}$ (from lone pair of electron in the oxygen and nitrogen atom). After adding $\mathrm{NaBH}_{4}$, the band at $317 \mathrm{~nm}$ immediately red shifted to $400 \mathrm{~nm}$ due to the generation of 4-nitrophenate anions in the system. Also, the color of the solution was changed from light yellow to yellow-green. In the absence of AuNPs as a catalyst, this peak remained unaltered even after $10 \mathrm{~h}$ Figure 6 and this indicating that; the reducing agent $\mathrm{NaBH}_{4}$ itself cannot reduce the 4-nitrophenolate ion and the reaction rates can be assumed to be independent of borohydride so the reduction is not achievable in the presence of $\mathrm{NaBH}_{4}$ alone.

After the addition of AuNPs capped by sodium citrate to the solution and in order to follow the kinetics of the reduction reaction, the change in the intensity of absorption of nitrophenolate was monitored using UV-visible spectrophotometry at regular time intervals. Sodium borohydried reduces water to hydrogen

$$
\mathrm{NaBH}_{4}+2 \mathrm{H}_{2} \mathrm{O} \rightarrow \mathrm{NaBO}_{2}+4 \mathrm{H}_{2} .
$$

The reduction reaction is carried out by the hydrogen and involves the production of hydrogen gas seen in the form of bubbles. There is a concomitant emergence of a peak at 310 and $230 \mathrm{~nm}$ which corresponding to the formation of 4-aminophenol Figure 7. Continuous reduction in the intensity of the peak at $400 \mathrm{~nm}$ shows the consumption of 4-nitrophenol. The reaction mechanism can be reasoned by the inherent hydrogen adsorption, desorption characterics of Au nanoparticle. The AuNPs shuttle the hydrogen transport between $\mathrm{NaBH}_{4}$ and 4-nitrophenol. The shuttling behaviors can be reasoned that the AuNPs adsorbs hydrogen from the $\mathrm{NaBH}_{4}$ and efficiently release during the reduction reaction and hence AuNPs acts as a hydrogen carrier in this reduction reaction Scheme 1.

The same behaviors were observed after adding the AuNPs capped be CTAB Figure 8 and chitosan Figure 9 except that the rate reaction. The reaction was setup in such a way that pseudo first order rate kinetics can be used to model the reaction. Pseudo first order law $K^{\prime}(A)=-\frac{\mathrm{d} A}{\mathrm{~d} t}$. where $K^{\prime}=k\left[B_{o}\right]$. The apparent rate constant is calculated from the decrease of the peak intensity of nitrophenol at $400 \mathrm{~nm}$ (the slope of the curve in Figure 10 and it is found to be $0.6 \times 10^{-3}, 1.9 \times 10^{-3}$,

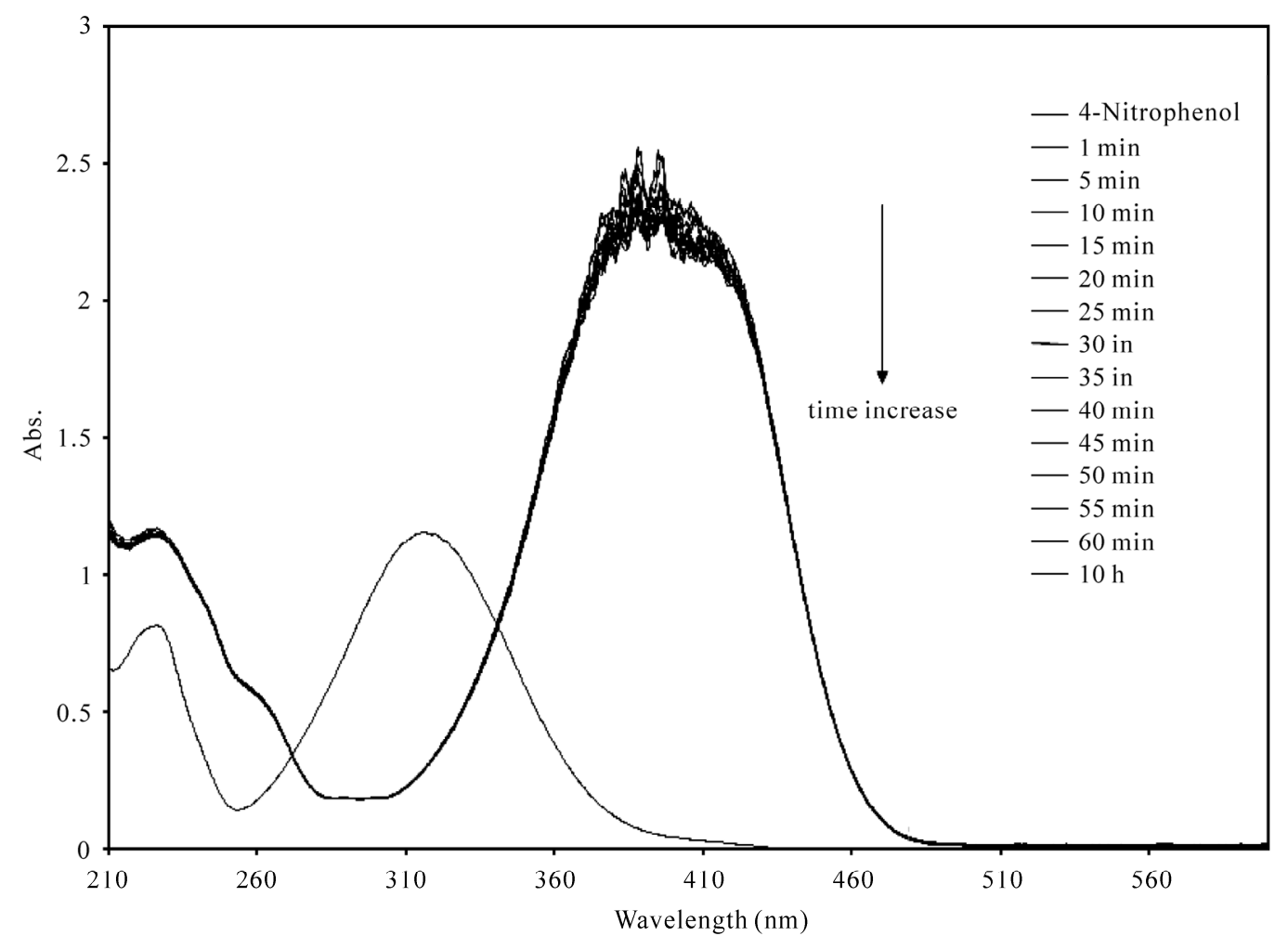

Figure 6. UV-vis spectrum of 4-nitrophenol using sodium borohydried as a catalyst at different time. 


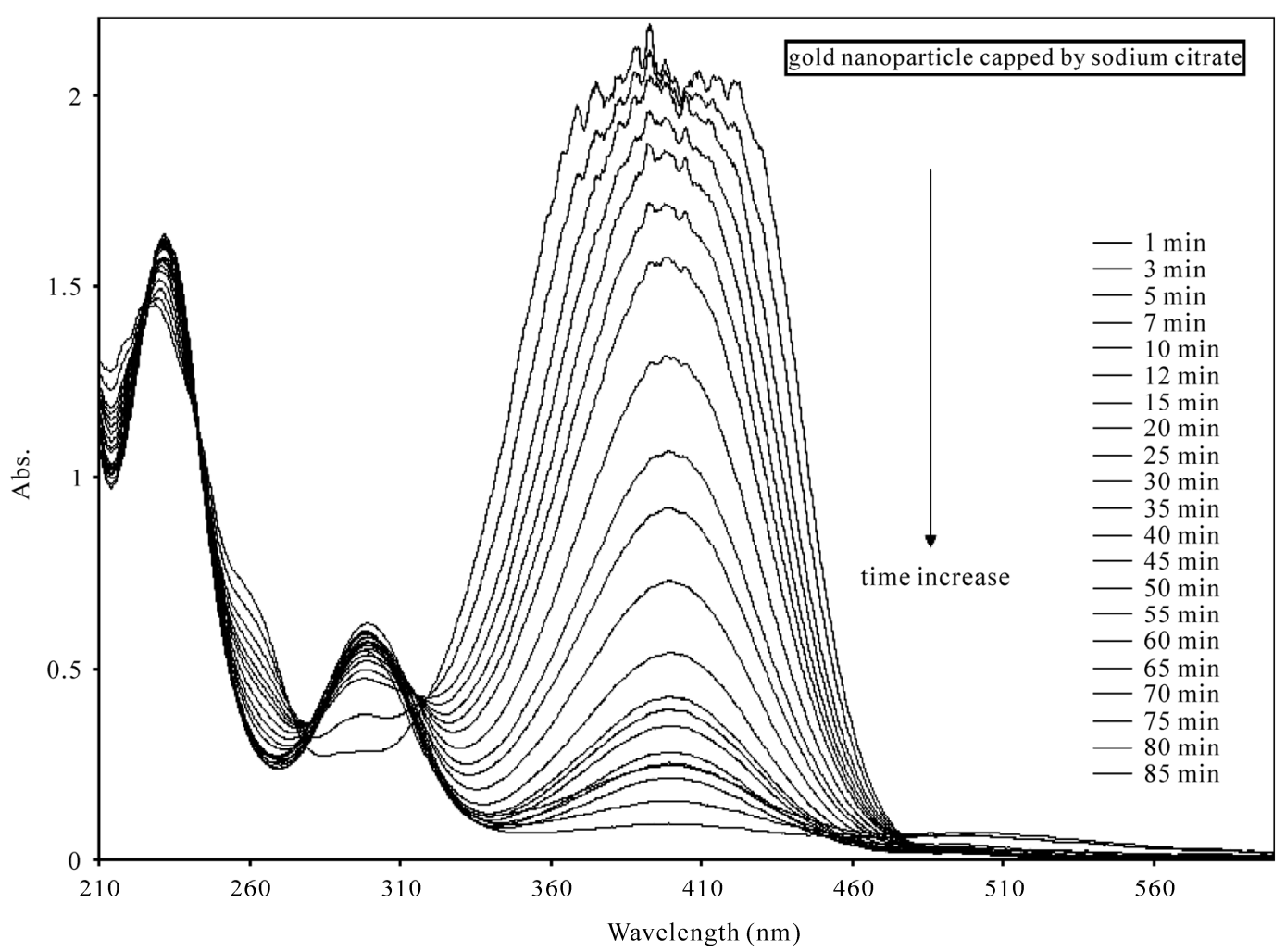

Figure 7. UV-vis spectrum of 4-nitrophenol using sodium borohydried and AuNPs capped by sodium citrate as a catalyst at different times.

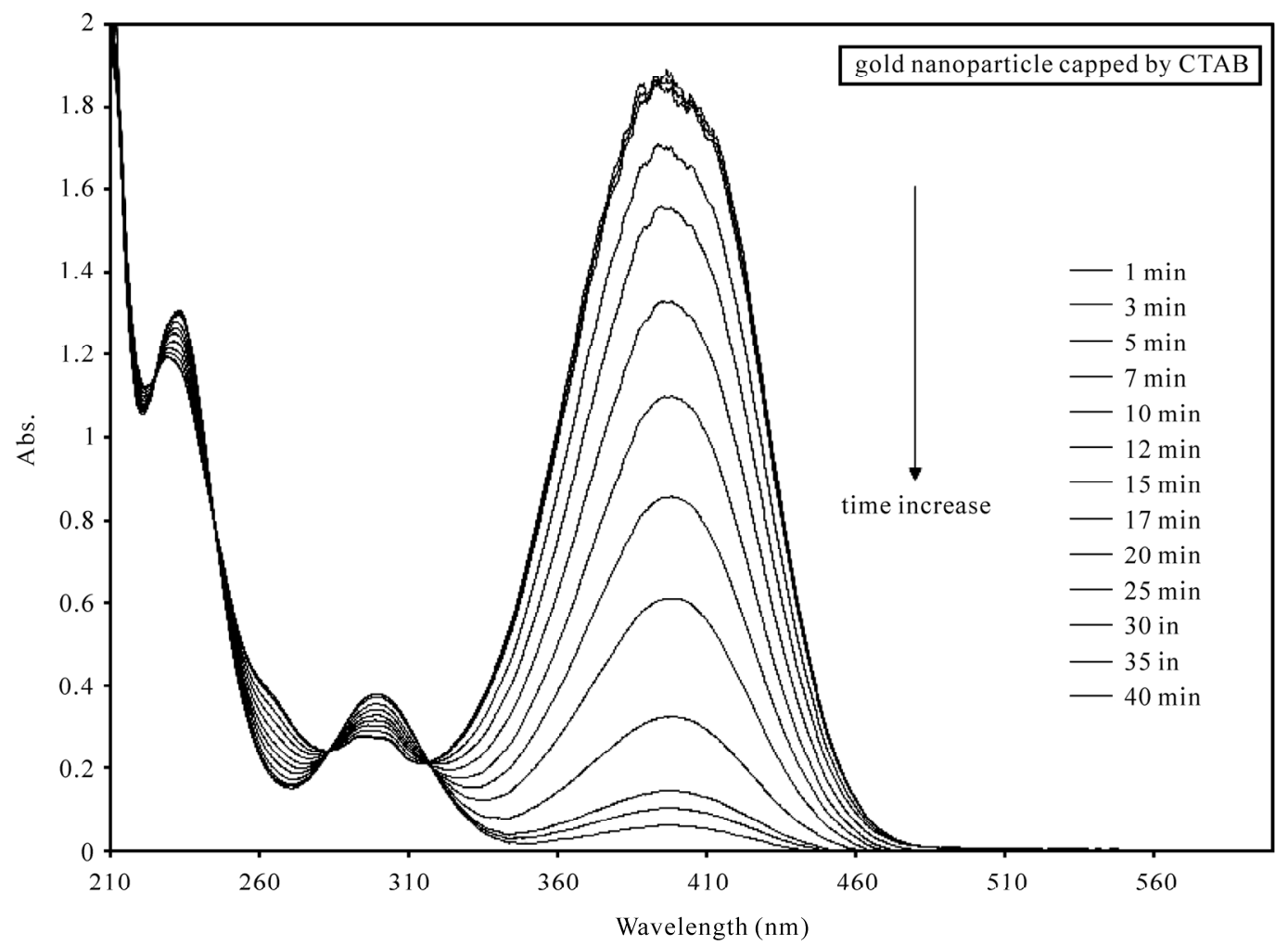

Figure 8. UV-vis spectrum of 4-nitrophenol using sodium borohydried and AuNPs capped by CTAB as a catalyst. 


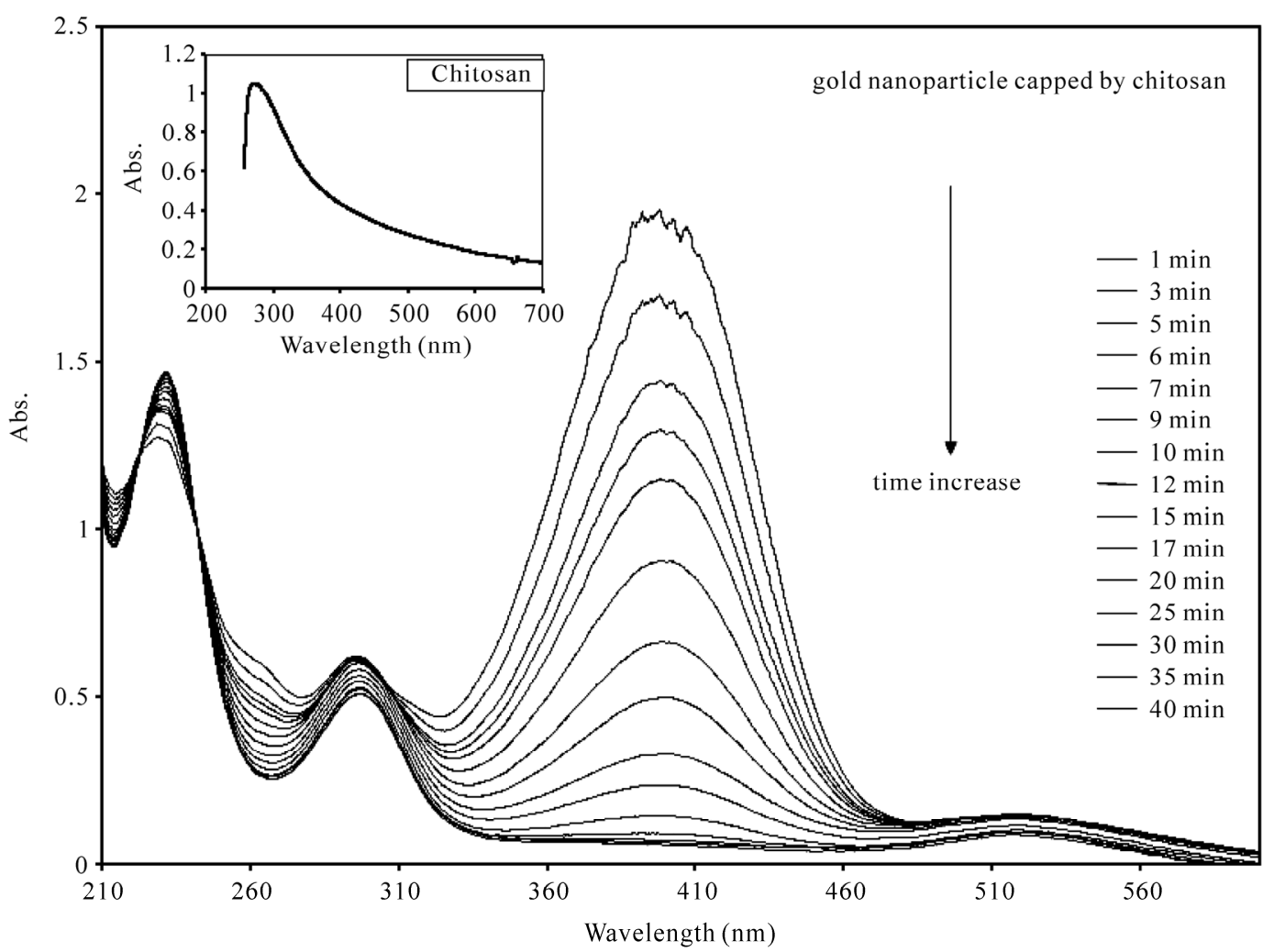

Figure 9. UV-vis spectrum of 4-nitrophenol using sodium borohydried and AuNPs capped by chitosan as a catalyst.

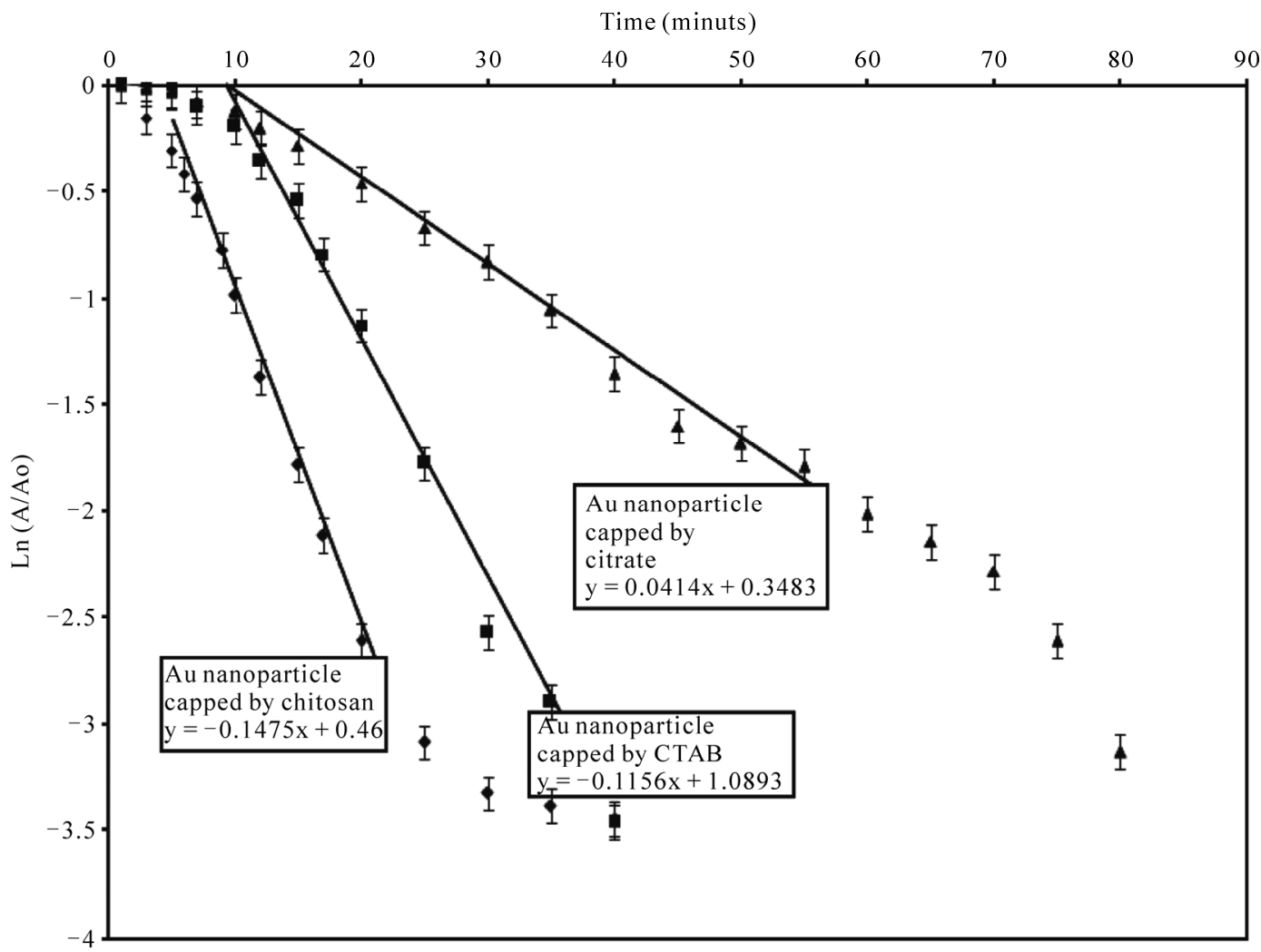

Figure 10. UV-Vis absorption changes vs. time in seconds for the disappearance of 4-nitrophenol absorption at $400 \mathrm{~nm}$. 


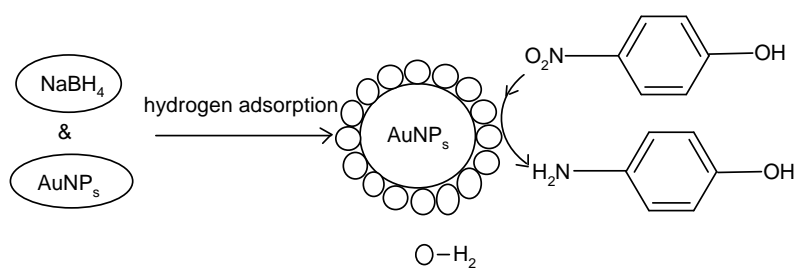

Scheme 1.

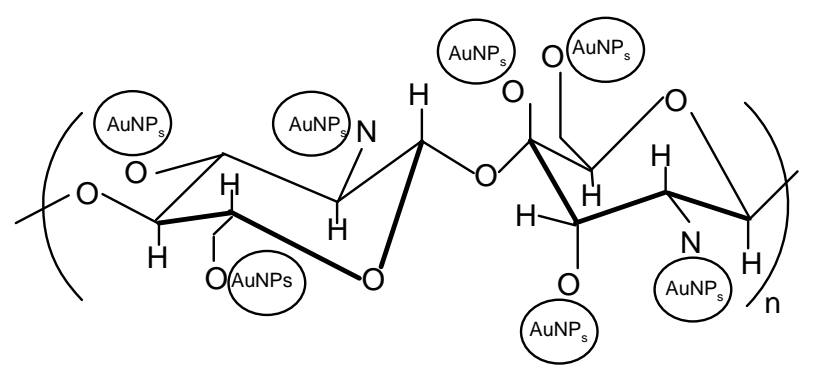

Structure 1 of AuNPs capped by chitosan.

and $2.4 \times 10^{-3} \mathrm{~S}^{-1}$ for AuNPs capped by sodium citrate, $\mathrm{CTAB}$ and chitosan, respectively.

It was found that was higher in case of chitosan and it is demonstrate that the AuNPs capped by chitosan is a highly effective carrier for catalysis. This seems obvious when we consider that the mobility of $\mathrm{NH}$ and $\mathrm{OH}$ groups on the AuNPs-chitosan increase the surface activity of gold nanoparticles Structure 1.

\section{Conclusions}

The rate of the gold nanoparticle reduction of 4-nitrophenol with sodium borohydried is faster in case of AuNPs capped by chitiosan because the surface activity is more active in the catalytic activity application. So that chitosan brush particles will work more effectively as a template for gold in the water solution compared to other capping.

\section{Acknowledgements}

The author expresses their thanks to Professor M. A. El-Sayed and his group, LDL, Gatech for helping me during preparation this work.

\section{References}

[1] T. Xu, N. Zhang, H. L. Nichols, D. L. Shi and X. J. Wen, "Modification of Nanostructured Materials for Biomedical Applications," Materials Science and Engineering: $C$, Vol. 27, No. 3, April 2007, pp. 579-594. doi:10.1016/j.msec.2006.05.029

[2] K. Xu, J. Huang, Z. Ye, Y. Ying and Y. Li, "Recent Development of Nano-Materials Used in DNA Biosensors,"
Sensors, Vol. 9, No. 7, 2009, pp. 5534-5557. doi:10.3390/s90705534

[3] A. Józefczak and A. Skumiel, "Ultrasonic Investigation of Magnetic Nanoparticles Suspension with PEG Biocompatible Coating," Journal of Magnetism and Magnetic Materials, Vol. 323, No. 11, June 2011, pp. 15091516. doi:10.1016/j.jmmm.2011.01.009

[4] S. Thangavel and R. Ramaraj, "Electroless Synthesis of Multibranched Gold Nanostructures Encapsulated by Poly(o-phenylenediamine) in Nafion," Journal of Colloid and Interface Science, Vol. 355, No. 2, March 2011, pp. 293-299. doi:10.1016/j.jcis.2010.12.035

[5] R. Güzel, Z. Üstündağ, H. Ekşi, S. Keskin, B. Taner, Z. G. Durgun, A. A. Turan and A. O. Solak, "Effect of Au and $\mathrm{Au} @$ Ag Core-Shell Nanoparticles on the SERS of Bridging Organic Molecules," Journal of Colloid and Interface Science, Vol. 351, No. 1, Novemner 2010, pp. 3542.

[6] O. Estévez-Hernández, E.M. Molina-Trinidad, P. Santiago-Jacinto, L. Rendón and E. Reguera, "Gold Nanoparticles Conjugated to Benzoylmercaptoacetyltriglycine and 1-Cysteine Methylester," Journal of Colloid and Interface Science, Vol. 350, No. , 2010, pp. 161-167.

[7] J. Wang and W. De Zhang, "Sputtering Deposition of Gold Nanoparticles onto Vertically Aligned Carbon Nanotubes for Electroanalysis of Uric Acid," Journal of Electroanalytical Chemistry, Vol. 654, No. 1-2, May 2011, pp. 79-84. doi:10.1016/j.jelechem.2011.01.023

[8] L. Wang, F. Montagne, P. Hoffmann, H. Heinzelmann and R. Pugin, "Hierarchical Positioning of Gold Nanoparticles into Periodic Arrays Using Block Copolymer Nanoring Templates," Journal of Colloid and Interface Science, Vol. 356, No. 2, April 2011, pp. 496-504. doi:10.1016/i.jcis.2010.12.081

[9] I. H. Hsu, W. H. Chen, T. K. Wu and Y. C. Sun, "Gold nanoparticle-Based Inductively Coupled Plasma Mass Spectrometry Amplification and Magnetic Separation for the Sensitive Detection of a Virus-Specific RNA Sequence," Journal of Chromatography A, Vol. 1218, No. 14, April 2011, pp. 1795-1801. doi:10.1016/j.chroma.2011.02.005

[10] Z. Guo, X. Fan, L. Liu, Z. Bian, C. Gu, Y. Zhang, N. Gu, D. Yang and J. Zhang, "Achieving High-Purity Colloidal Gold Nanoprisms and Their Application as Biosensing Platforms," Journal of Colloid and Interface Science, Vol. 348, No. 1,August 2010, pp. 29-36. doi:10.1016/j.jcis.2010.04.013

[11] S. Nath, S. Jana, M. Pradhan and T. Pal, "Ligand-Stabilized Metal Nanoparticles in Organic Solvent," Journal of Colloid and Interface Science, Vol. 341, No. 2, 2010, pp. 333-352.

[12] J. R. Peralta-Videa, L. Zhao, M. L. Lopez-Moreno, G. Rosa, J. Hong and J. L. Torresdey, "Nanomaterials and the Environment: A Review for the Biennium 20082010," Journal of Hazardous Materials, Vol. 186, No. 1, 2011, pp. 1-15. doi:10.1016/j.jhazmat.2010.11.020

[13] E. Falletta, F. Ridi, E. Fratini, C. Vannucci, P. Canton, S. Bianchi, V. Castelvetro and P. Baglioni, "A Tri-Block 
Copolymer Templated Synthesis of Gold Nanostructures," Journal of Colloid and Interface Science, Vol. 357, No. 1, May 2011, pp. 88-94. doi:10.1016/j.jcis.2010.12.074

[14] Y. C. Lin, B. Y. Yu, W. C. Lin, S. H. Lee, C. H. Kuo and J. J. Shyue, "Tailoring the Surface Potential of Gold Nanoparticles with Self-Assembled Monolayers with Mixed Functional Groups," Journal of Colloid and Interface Science, Vol. 340, No. 1, December 2009, pp. 126-130. doi:10.1016/j.jcis.2009.08.014

[15] W. K. Lee, S. H. Cha, K. H. Kim, B. W. Kim and J. C. Lee, "Shape-Controlled Synthesis of Gold Icosahedra and Nanoplates Using Pluronic P123 Block Copolymer and Sodium Chloride," Journal of Solid State Chemistry, Vol. 182, No. 12, December 2009, pp. 3243-3248. doi:10.1016/j.jssc.2009.09.020

[16] C. Contado and R. Argazzi, "Size Sorting of Citrate Reduced Gold Nanoparticles by Sedimentation Field-Flow Fractionation," Journal of Chromatography A, Vol. 1216, No. 52, December 2009, pp. 9088-9098. doi:10.1016/j.chroma.2009.08.026

[17] J. P. Douliez, B. Novales and C. Gaillard, "Synthesising Gold Nanoparticles within Bola Fatty Acid Nanosomes," Journal of Colloid and Interface Science, Vol. 337, No. 2, September 2009, pp. 610-613. doi:10.1016/j.jcis.2009.05.042

[18] S. I. Stoeva A. B. Smetana, C. M. Sorensen and K. J. Klabunde, "Gram Scale Synthesis of Aqueous Gold Colloids Stabilized by Various Ligands," Journal of Colloid and Interface Science, Vol. 309, No. 1, May 2007, pp. 94-98. doi:10.1016/i.jcis.2006.12.064

[19] Y. Sun and C. Lei, "Synthesis of Out-of-Substrate Au-Ag Nanoplates with Enhanced Stability for Catalysis," Angewandte Chemie, Vol. 121, No. 37, September 2009, pp. 6956-6959. doi:10.1002/ange.200902305

[20] N. Yan, J. Zhang, Y. Yuan, G. T. Chen, P. J. Dyson, Z. C. $\mathrm{Li}$ and Y. Kou, "Thermoresponsive Polymers Based on Poly-Vinylpyrrolidone: Applications in Nanoparticle Catalysis," Chem Commun, Vol. 46, No. 10, 2010, pp. 16311633.

[21] S. S. Kinge and M. C. Calama, "Gold Nanoparticle Assemblies through Hydrogen-Bonded Supramolecular Mediators," Langmuir, Vol. 23, No. 17, 2007, pp. 87728777. doi:10.1021/la700514u

[22] S. S. Kumar, C. S. Kumar, J. Mathiyarasu and K. L. Phani, "Stabilized Gold Nanoparticles by Reduction Using 3,4-Ethylenedioxythiophene-Polystyrenesulfonate in Aqueous Solutions: Nanocomposite Formation, Stability, and Application in Catalysis," Langmuir. Vol. 23, No. 6, 2007, pp. 3401-3408. doi:10.1021/la063150h

[23] M. Montalti, L. Prodi, N. Zaccheroni, M. Beltrame, T. Morotti and S. Quici, "Stabilization of Gold Nanoparticles by Metal Ions Complexation," New Journal of Chemistry, Vol. 31, No. 1, 2007, pp.102-108.

[24] N. Nilius, M. V. Ganduglia-Pirovano, V. Brázdová, M. Kulawik, J. Sauer and H.-J. Freund, "Electronic Properties and Charge State of Gold Monomers and Chains Adsorbed on Alumina Thin Films on NiAl(110)," Physi- cal Review B, Vol. 81, No. 4, 2010, pp, 45422-45429.

[25] M. T. Javed, N. Irfan and B. M. Gibbs, "Control of Combustion-Generated Nitrogen Oxides by Selective Non-Catalytic Reduction," Journal of Environmental Management, Vol. 83, No. 3, May 2007, pp. 251-289. doi:10.1016/i.jenvman.2006.03.006

[26] E. J. Beckman, "Supercritical and Near-Critical $\mathrm{CO}_{2}$ in Green Chemical Synthesis and Processing," The Journal of Supercritical Fluids, Vol. 28, No. 2-3, March 2004, pp. 121-191. doi:10.1016/S0896-8446(03)00029-9

[27] M. Sahimi and T. T. Tsotsis, "A Percolation Model of Catalyst Deactivation by Sit Coverage and Pore Blockage," Journal of Catalysis, Vol. 96, No. 2, December 1985, pp. 552-562. doi:10.1016/0021-9517(85)90323-9

[28] R. R. Melkote and K. F. Jensen, "Models for Catalytic Pore Plugging, Application to Hydrodemetallation," Chemical Engineering Science, Vol. 44, No. 3, 1989, pp. 649-663. doi:10.1016/0009-2509(89)85041-9

[29] G. C. Bond, "Gold: A Relatively New Catalyst," Catalysis Today, Vol. 72, No. 1-2, February 2002, pp. 5-9. doi:10.1016/S0920-5861(01)00522-3

[30] G. J. Hutchings, "Nanocrystalline Gold Catalysts: A Reflection on Catalyst Discovery and the Nature of Active Sites," Gold Bulletin, Vol. 42, No. 4, 2009, pp. 260-266. doi:10.1007/BF03214947

[31] P. T. Anastas and J. C. Warner, "Green Chemistry: Theory and Practice," Oxford University Press, New York, 1998.

[32] X. G. Zhang, D. Y. Teng, Z. M. Wu, X. Wang, Z. Wang, D. M. Yu and C. X. Li, "PEG-Grafted Chitosan Nanoparticles as an Injectable Carrier for Sustained Protein Release," Journal of Materials Science: Materials in Medicine, Vol. 19, No. 12, 2008, pp. 3525-3533. doi:10.1007/s 10856-008-3500-8

[33] A. S. Karikari, W. F. Edwards, J. B. Mecham and T. E. Long, "Influence of Peripheral Hydrogen Bonding on the Mechanical Properties of Photo-Cross-Linked StarShaped Poly(D,L-Lactide) Networks," Biomacromolecules, Vol. 6, No. 5, 2005, pp. 2866-2874. doi: $10.1021 / \mathrm{bm} 050375 \mathrm{i}$

[34] R. Song, R. Xuea, L. He, Y. Liu and Q. Xiao, "The Structure and Properties of Chitosan/Polyethylene Glycol/Silica Ternary Hybrid Organic-Inorganic Films," Chinese Journal of Polymer Science Vol. 26, No. 5, 2008, pp. 621-630. doi:10.1142/S0256767908003357

[35] J. G. Rouse and M. E. Van Dyke, "A Review of Keratin-Based Biomaterials for Biomedical Applications," Materials, Vol. 3, No. 2, 2010, pp. 999-1014. doi:10.3390/ma3020999

[36] M. Bodnar, J. F. Hartmann and J. Borbely, "Synthesis and Study of Cross-Linked Chitosan-N-Poly(ethylene glycol) Nanoparticles," Biomacromolecules, Vol. 7, No. 11, 2006, pp. 3030-3036. doi:10.1021/bm0605053

[37] K. Esumi, N. Takei and T. Yoshimura, "AntioxidantPotentiality of Gold-Chitosan Nanocomposites," Colloids and Surfaces B: Biointerfaces, Vol. 32, No. 2, October 2003, pp. 117-123. doi:10.1016/S0927-7765(03)00151-6 
[38] S. Wunder, F. Polzer, Y. Lu, Y. Mei and M. Ballauff, "Kinetic Analysis of Catalytic Reduction of 4-Nitrophenol by Metallic Nanoparticles Immobilized in Spherical Polyelectrolyte Brushes," Journal of Physical Chemistry C, Vol. 114, No. 19, 2010, pp. 8814-8820.
[39] M. Haruta, "Catalysis of Gold Nanoparticles Deposited on Metal Oxides," CATTECH, Vol. 6, No. 3, 2002, pp. 102-115. 